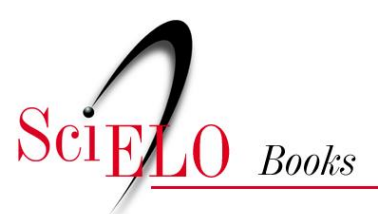

\title{
Ordem Anguilliformes
}

\author{
Ana Cristina Teixeira Bonecker \\ Claudia Akemi Pereira Namiki \\ Márcia Salustiano de Castro \\ Paula Nepomuceno Campos
}

\section{SciELO Books / SciELO Livros / SciELO Libros}

BONECKER, ACT., et al. Ordem Anguilliformes. In Catalogo dos estágios iniciais de desenvolvimento dos peixes da bacia de Campos [online]. Curitiba: Sociedade Brasileira de Zoologia, 2014, pp. 11-30. Zoologia: guias e manuais de identificação series. ISBN 978-85-98203-10-2.

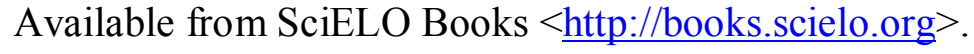

\section{(c) (1) @(2)}

All the contents of this chapter, except where otherwise noted, is licensed under a Creative Commons Attribution-Non Commercial-ShareAlike 3.0 Unported.

Todo o conteúdo deste capítulo, exceto quando houver ressalva, é publicado sob a licença Creative Commons Atribuição Uso Não Comercial - Partilha nos Mesmos Termos 3.0 Não adaptada.

Todo el contenido de este capítulo, excepto donde se indique lo contrario, está bajo licencia de la licencia Creative Commons Reconocimento-NoComercial-CompartirIgual 3.0 Unported. 


\section{ORDEM ANGUILLIFORMES}

A ordem Anguilliformes é composta por 15 famílias com aproximadamente 791 espécies. Essa ordem compreende as enguias e moreias, que durante os estágios iniciais de desenvolvimento possuem larvas denominadas leptocephalus. Essas larvas possuem cabeça diminuta e corpo lateralmente comprimido e transparente, permitindo a visualização dos miômeros. As leptocephali dessa ordem podem variar de exemplares pequenos a muito grandes. Possuem nadadeira caudal pequena e contínua com as nadadeiras dorsal e anal. Não possuem nadadeiras pélvicas. As nadadeiras peitorais podem ser presentes ou ausentes, sendo de tamanho reduzido em alguns casos.

Nesse estudo a ordem Anguilliformes é representada pelas famílias Chlopsidae, Muraenidae, Ophichthidae, Congridae, Nemichthyidae e Nettastomatidae. 


\section{Família Chlopsidae}

A família Chlopsidae é marinha e ocorre nas regiões tropicais e subtropicais dos oceanos Atlântico, Índico e Pacífico. Compreende oito gêneros com 18 espécies. As larvas podem alcançar até $100 \mathrm{~mm}$ de comprimento e possuem corpo alto e cauda arredondada. O intestino é reto e curto, chegando a menos da metade do corpo. A nadadeira dorsal é longa começando no primeiro quinto do corpo.

No Brasil já foram identificadas seis espécies nas fases de larva e adulto: Nesse estudo são contempladas as espécies Chlopsis dentatus, Kaupichthys hyoproroides e Kaupichthys nuchalis. 


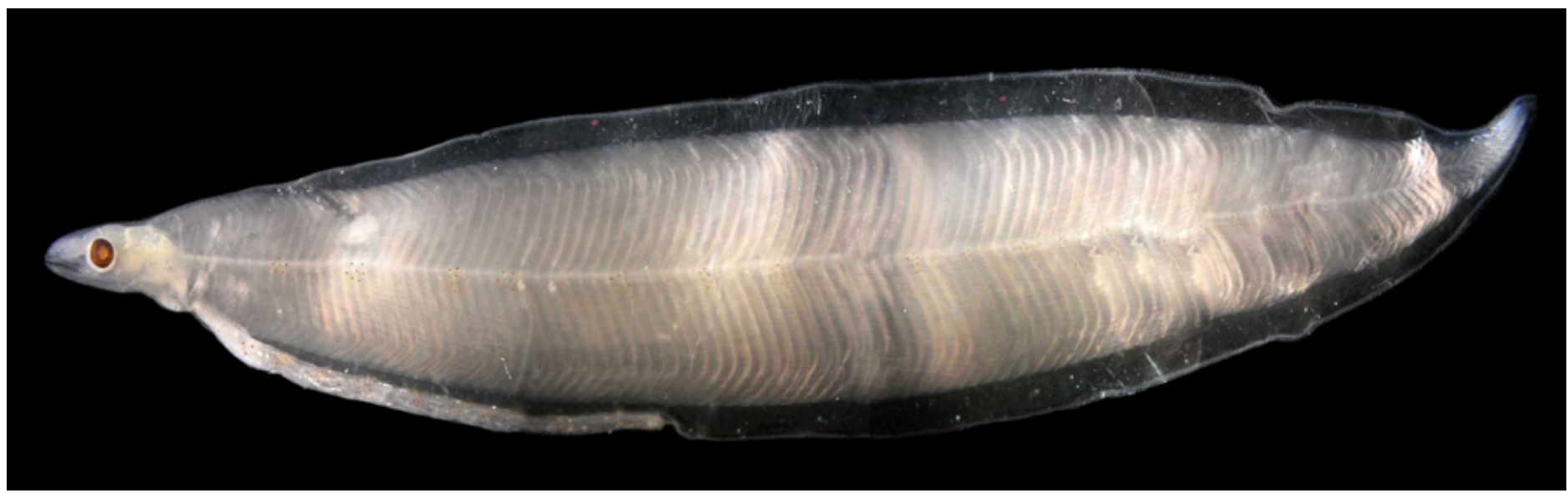

Figura 1 - A: DZUFRJ 22079; CP 52,0 mm. Vista geral

\section{Chlopsis dentatus (Seale, 1917)}

A principal característica para identificação dessa espécie é a presença de grupos de pequenos melanóforos ao longo da linha lateral, desde logo depois da cabeça até o final da cauda. Presença de melanóforos na margem superior do intestino. O intestino é curto alcançando aproximadamente $42 \%$ do comprimento total do corpo. Número total de miômeros: 114-119.

Habitat: espécie marinha e demersal. Ocorre entre 64 e $366 \mathrm{~m}$ de profundidade.

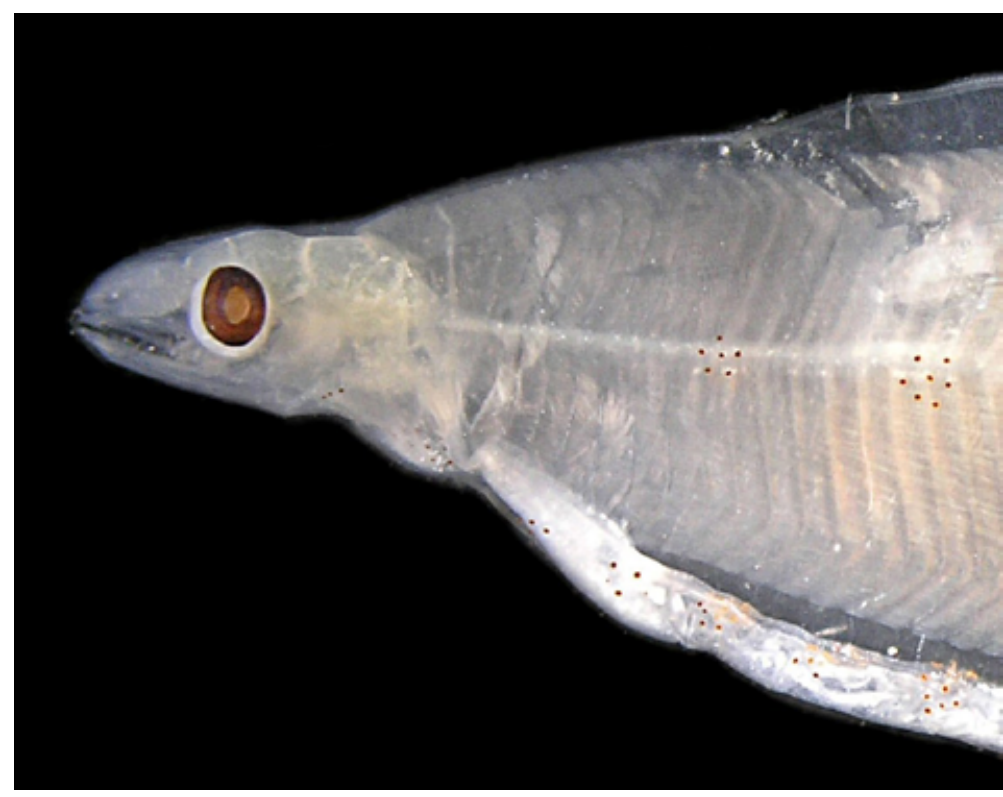

Figura 1 - B: Destaque dos grupos de pequenos melanóforos ao longo da linha lateral.

\section{Georreferencimento}

\begin{tabular}{|l|l|l|l|l|l|l|l|l|}
\hline DZUFRJ & Latitude (S) & Longitude (W) & Data & $\begin{array}{l}\text { Tipo de } \\
\text { arrasto }\end{array}$ & $\begin{array}{l}\text { Profundidade } \\
\text { de coleta }\end{array}$ & Rede & $\begin{array}{l}\text { Malha } \\
\text { ( } \boldsymbol{\mu m})\end{array}$ & $\begin{array}{l}\mathbf{N}^{\circ} \text {. de } \\
\text { inds. }\end{array}$ \\
\hline 22079 & $22^{\circ} 31^{\prime} 40,9^{\prime \prime}$ & $040^{\circ} 02^{\prime} 39,6^{\prime \prime}$ & $07 / 11 / 2001$ & oblíquo & $1.000 \mathrm{~m}$ & $\begin{array}{l}\text { cilíndrico- } \\
\text { cônica }\end{array}$ & 500 & 1 \\
\hline
\end{tabular}

Referências: Smith, 1989a. 


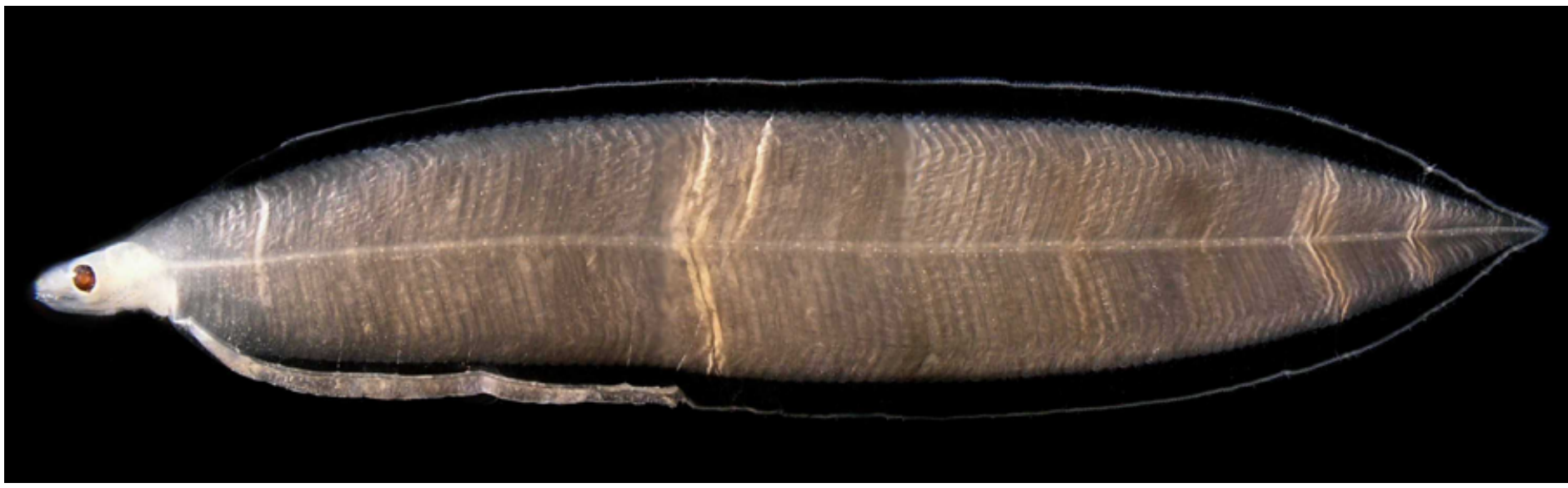

Figura 2 - A: Kaupichthys hyoproroides DZUFRJ 22078; CP 55,0 mm. Vista geral.

\section{Kaupichthys hyoproroides (Strömman, 1896)}

As principais características para identificação dessa espécie são: intestino curto (menos de $50 \%$ do comprimento total) e presença de melanóforos espalhados por todo o corpo. Apresenta uma mancha de pigmentos, no formato de meia-lua, abaixo do olho. Número total de miômeros: 113-120.

Habitat: espécie marinha, associada a formações coralinas. Vive em águas subtropicais em profundidades de até $95 \mathrm{~m}$.

Nome vulgar: Falsa moreia marrom.

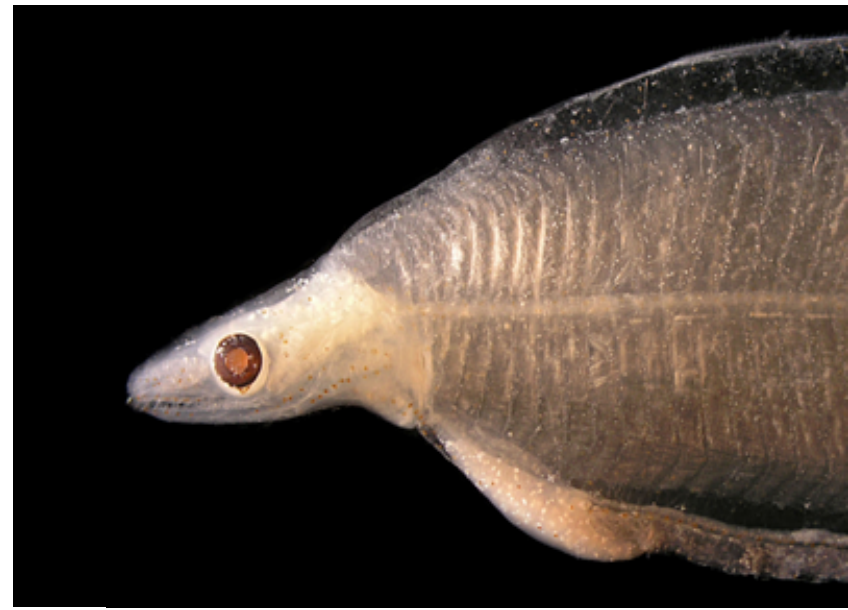

Figura 2 - B: Melanóforos espalhados pelo corpo.

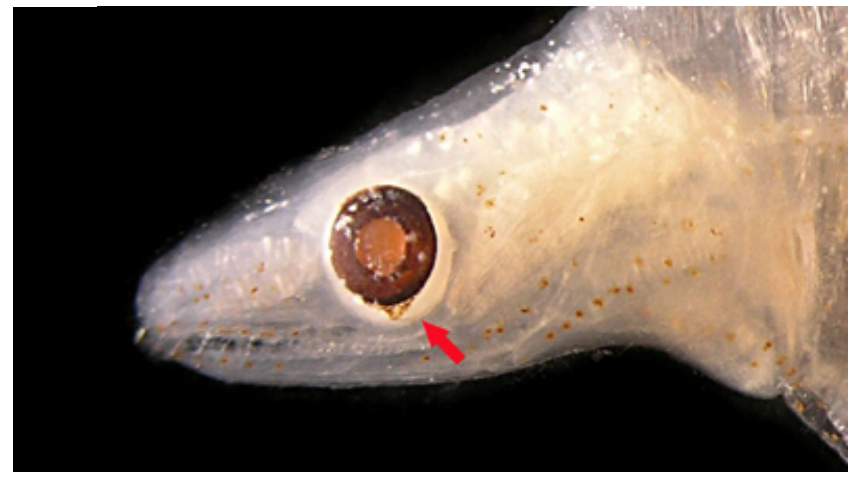

Figura 2 - C: Detalhe da cabeça com mancha de pigmentos no formato de meia-lua abaixo do olho.

Georreferenciamento

\begin{tabular}{|c|c|c|c|c|c|c|c|c|}
\hline DZUFR & Latitude (S) & Longitude (W) & Data & $\begin{array}{c}\text { Tipo de } \\
\text { arrasto }\end{array}$ & $\begin{array}{c}\text { Profundidade } \\
\text { de coleta }\end{array}$ & Rede & $\begin{array}{c}\text { Malha } \\
\text { ( } \begin{array}{c}\boldsymbol{N}^{\circ} \text { ) } \\
\text { inds. }\end{array}\end{array}$ \\
\hline 408 & $22^{\circ} 33^{\prime} 47,7^{\prime \prime}$ & $040^{\circ} 12^{\prime} 20,5^{\prime \prime}$ & $17 / 05 / 2002$ & oblíquo & $50 \mathrm{~m}$ & bongô & 330 & 1 \\
\hline 1290 & $22^{\circ} 02^{\prime} 30,0^{\prime \prime}$ & $039^{\circ} 49^{\prime} 41,2^{\prime \prime}$ & $12 / 05 / 2002$ & oblíquo & até a termoclina & bongô & 500 & 1 \\
\hline 7591 & $22^{\circ} 31^{\prime} 40,9^{\prime \prime}$ & $040^{\circ} 02^{\prime} 39,6^{\prime \prime}$ & $07 / 11 / 2001$ & oblíquo & $1.000 \mathrm{~m}$ & cilíndrico-cônica & 500 & 1 \\
\hline 22078 & $22^{\circ} 32^{\prime} 50,0^{\prime \prime}$ & $040^{\circ} 04^{\prime} 09,9^{\prime \prime}$ & $06 / 11 / 2001$ & oblíquo & $1.000 \mathrm{~m}$ & cilíndrico-cônica & 500 & 2 \\
\hline
\end{tabular}

Referências: Smith, 1989a; Castro \& Bonecker, 2005; Castro \& Bonecker, 2006a. 


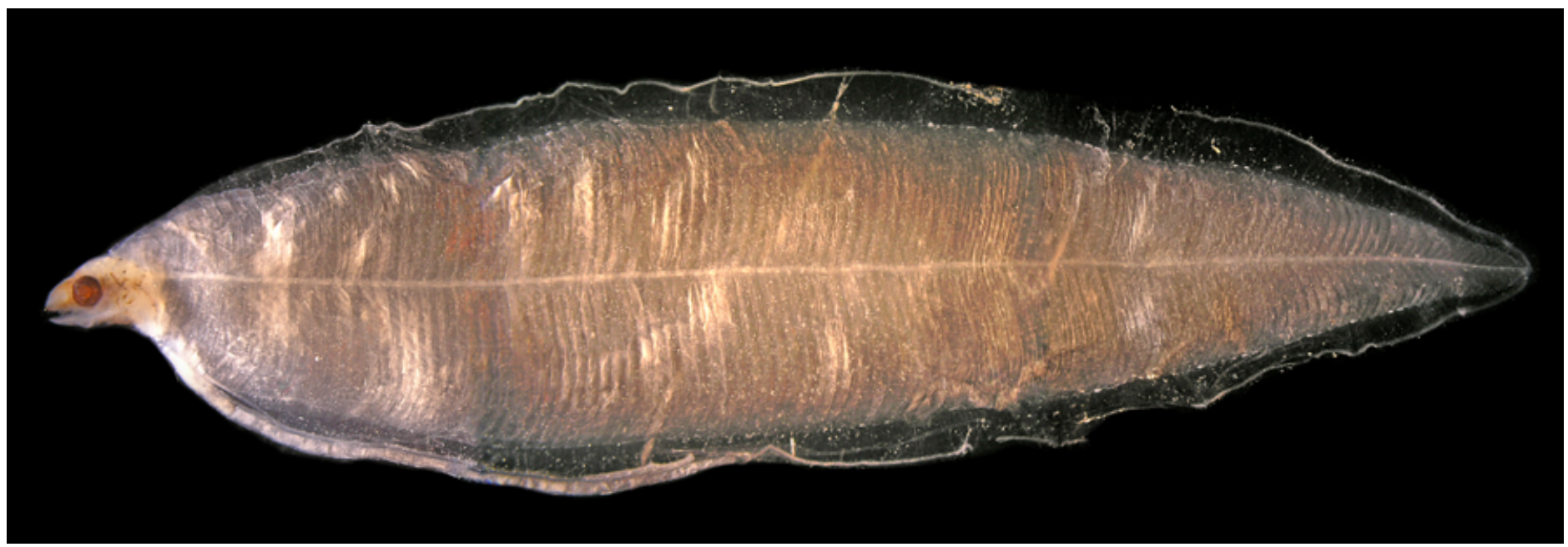

Figura 3 - A: Kaupichthys nuchalis DZUFRJ 21541; CP 52,0 mm. Vista geral.

\section{Kaupichthys nuchalis Böhlke, 1967}

A principal característica para separar essa espécie dos outros representantes da família é que o nefros termina um pouco antes do ânus. Possui melanóforos muito pequenos na região da linha lateral, desde o ânus até a cauda, a cada dois ou três miômeros. Os melanóforos também estão presentes na cabeça, na frente e atrás do olho. Número total de miômeros: 121-125.

Habitat: espécie marinha, associada a formações coralinas. Vive em águas tropicais em profundidades de até $77 \mathrm{~m}$, mas já foi capturada entre 604-732 m. Ainda não havia sido registrada para o Brasil.

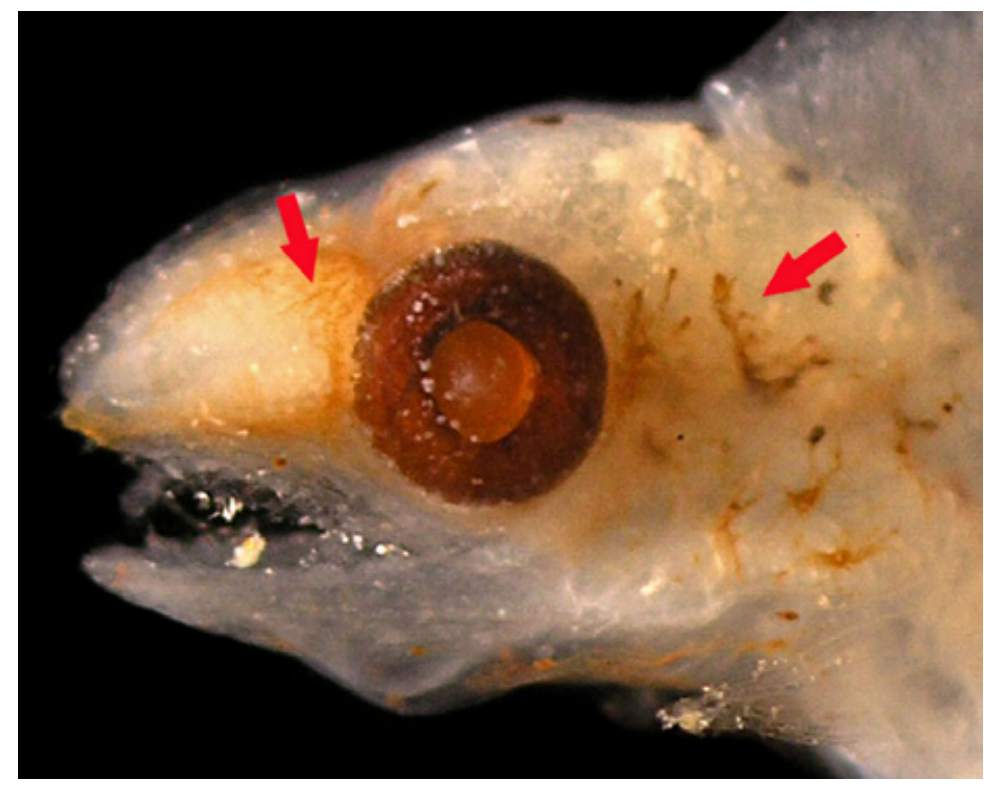

Figura 3 - B: Detalhe da cabeça com melanóforos na frente e atrás do olho.

\section{Georreferenciamento}

\begin{tabular}{|c|c|c|c|c|c|c|c|c|}
\hline DZUFRJ & Latitude (S) & Longitude (W) & Data & $\begin{array}{c}\text { Tipo de } \\
\text { arrasto }\end{array}$ & $\begin{array}{c}\text { Profundidade } \\
\text { de coleta }\end{array}$ & Rede & $\begin{array}{c}\text { Malha } \\
\text { ( } \boldsymbol{\mu m} \text { ) }\end{array}$ & $\begin{array}{c}\mathbf{N}^{\circ} \text {. de } \\
\text { inds. }\end{array}$ \\
\hline 21541 & $22^{\circ} 31^{\prime} 58,9^{\prime \prime}$ & $040^{\circ} 02^{\prime} 53,4^{\prime \prime}$ & $07 / 11 / 2001$ & oblíquo & $1.000 \mathrm{~m}$ & $\begin{array}{c}\text { cilíndrico- } \\
\text { cônica }\end{array}$ & 500 & 1 \\
\hline
\end{tabular}

Referências: Smith, 1989a. 


\section{Família Muraenidae}

A família Muraenidae é marinha, mas algumas espécies ocasionalmente podem entrar em ambientes de água doce. Ocorre nos oceanos tropicais e temperados. Compreende 15 gêneros com 185 espécies. As larvas geralmente chegam no máximo a $100 \mathrm{~mm}$ de comprimento e o corpo é moderadamente alto. A cauda é arredondada e o intestino é um tubo reto alcançando a metade ou $3 / 4$ do comprimento padrão. Uma característica importante para a identificação é a nadadeira peitoral reduzida. Os gêneros e as espécies podem ser separados principalmente pela pigmentação e pela posição das nadadeiras dorsal e anal.

No Brasil já foram identificadas 19 espécies nas fases de larva e adulto. Nesse estudo é contemplada apenas a espécie Gymnothorax ocellatus. 


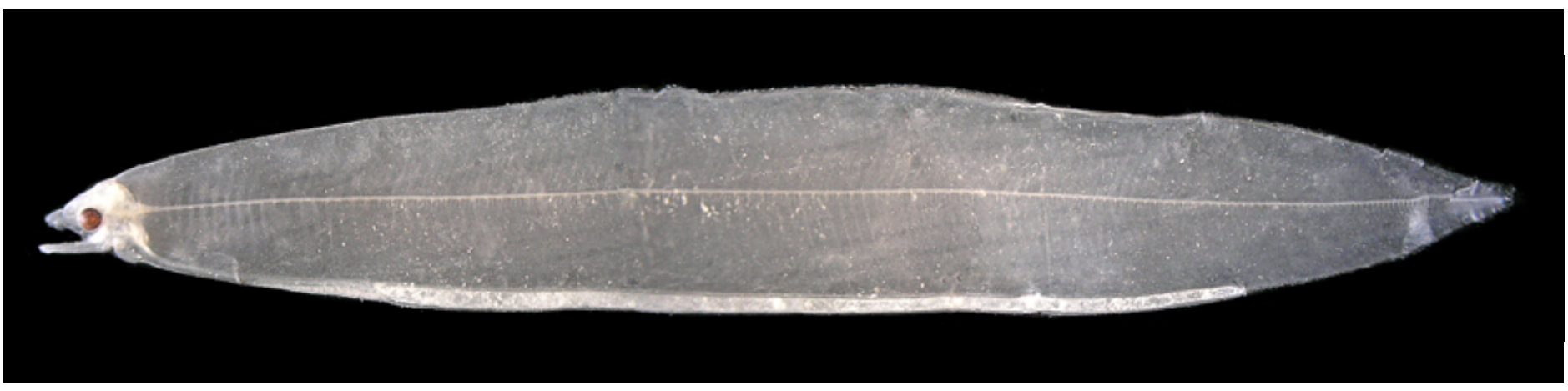

Figura 4: Gymnothorax ocellatus DZUFRJ 13694; CP 36,0 mm.

\section{Gymnothorax ocellatus Agassiz, 1831}

A nadadeira dorsal começa muito antes do ânus, entre os miômeros 22 e 32. Apresenta pigmentos nas regiões dorsal e ventral do intestino, nas bases das nadadeiras dorsal, anal, e caudal, e melanóforos na região dorsal, desde o miômero oito até o início da nadadeira dorsal. Número total de miômeros: 136-145.

Habitat: espécie marinha, associada a formações coralinas. Vive em águas tropicais até a profundidade de $160 \mathrm{~m}$. É muito comum no litoral brasileiro.

Nome vulgar: Moreia de areia.

\section{Georreferenciamento}

\begin{tabular}{|c|c|c|c|c|c|c|c|c|}
\hline DZUFRJ & Latitude (S) & Longitude (W) & Data & $\begin{array}{c}\text { Tipo de } \\
\text { arrasto }\end{array}$ & $\begin{array}{c}\text { Profundidade } \\
\text { de coleta }\end{array}$ & Rede & $\begin{array}{c}\text { Malha } \\
\text { ( } \boldsymbol{\mu m} \text { ) }\end{array}$ & $\begin{array}{c}\mathbf{N}^{\circ} \text {. de } \\
\text { inds. }\end{array}$ \\
\hline 494 & $22^{\circ} 31^{\prime} 27,0^{\prime \prime}$ & $040^{\circ} 16^{\prime} 56,0^{\prime \prime}$ & $17 / 05 / 2002$ & oblíquo & $600 \mathrm{~m}$ & $\begin{array}{c}\text { cilíndrico- } \\
\text { cônica }\end{array}$ & 500 & 1 \\
\hline 22077 & $22^{\circ} 33^{\prime} 37,0^{\prime \prime}$ & $040^{\circ} 19^{\prime} 10,0^{\prime \prime}$ & $17 / 05 / 2002$ & oblíquo & $50 \mathrm{~m}$ & bongô & 500 & 1 \\
\hline
\end{tabular}

Referências: Smith, 1989b; Castro \& Bonecker, 2005; Castro \& Bonecker, 2006a. 


\section{Família Ophichthidae}

A família Ophichthidae é marinha, mas algumas espécies ocasionalmente podem entrar em ambientes de água doce. Ocorre nos oceanos tropicais e temperados quentes. Compreende 52 gêneros com 290 espécies. As larvas são alongadas e frequentemente chegam no máximo a 100 $\mathrm{mm}$. Possuem no mínimo duas voltas no intestino, fígado dividido em dois ou três lóbulos com a vesícula gasosa presente no último lóbulo. Uma característica importante é que o nefros termina até 15 miômeros antes do ânus.

No Brasil já foram identificadas 29 espécies nas fases de larva e adulto. Nesse estudo foi contemplado o morfotipo Bascanichthyini sp. e a espécie Myrichthys ocellatus. 


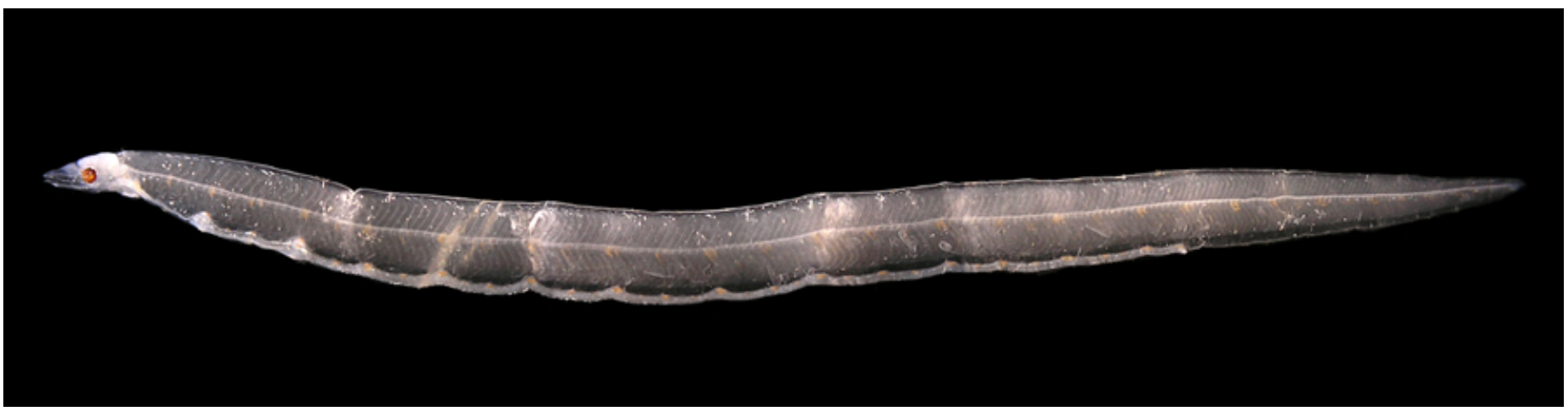

Figura 5: Bascanichthyini sp. DZUFRJ 592; CP 49,2 mm.

\section{Bascanichthyini sp.}

Os indivíduos da tribo Bascanichthyni têm o intestino e o nefros relativamente longos. A maioria das espécies desse grupo possui o intestino com voltas moderadas ou não pronunciadas. A pigmentação observada é pouco útil na identificação das espécies. No exemplar coletado nesse estudo, o nefros termina na última volta do intestino, junto com o ânus. Possui aproximadamente 37 grupos de pigmentos na região da linha lateral desde a cabeça até a cauda. Número total de miômeros: 220; número de miômeros pré-anal: 145.

Habitat: a maioria das espécies dessa tribo é marinha.

\section{Georreferenciamento}

\begin{tabular}{|c|c|c|c|c|c|c|c|c|}
\hline DZUFR & Latitude (S) & Longitude (W) & Data & $\begin{array}{c}\text { Tipo de } \\
\text { arrasto }\end{array}$ & $\begin{array}{c}\text { Profundidade } \\
\text { de coleta }\end{array}$ & Rede & $\begin{array}{c}\text { Malha } \\
\text { ( } \boldsymbol{\mu m})\end{array}$ & $\begin{array}{c}\mathbf{N} \text {. de } \\
\text { inds. }\end{array}$ \\
\hline 592 & $22^{\circ} 33^{\prime} 45,8^{\prime \prime}$ & $040^{\circ} 13^{\prime} 22,9^{\prime \prime}$ & $17 / 05 / 2002$ & oblíquo & $800 \mathrm{~m}$ & cilíndrico-cônica & 500 & 1 \\
\hline
\end{tabular}

Referências: Leiby, 1989. 


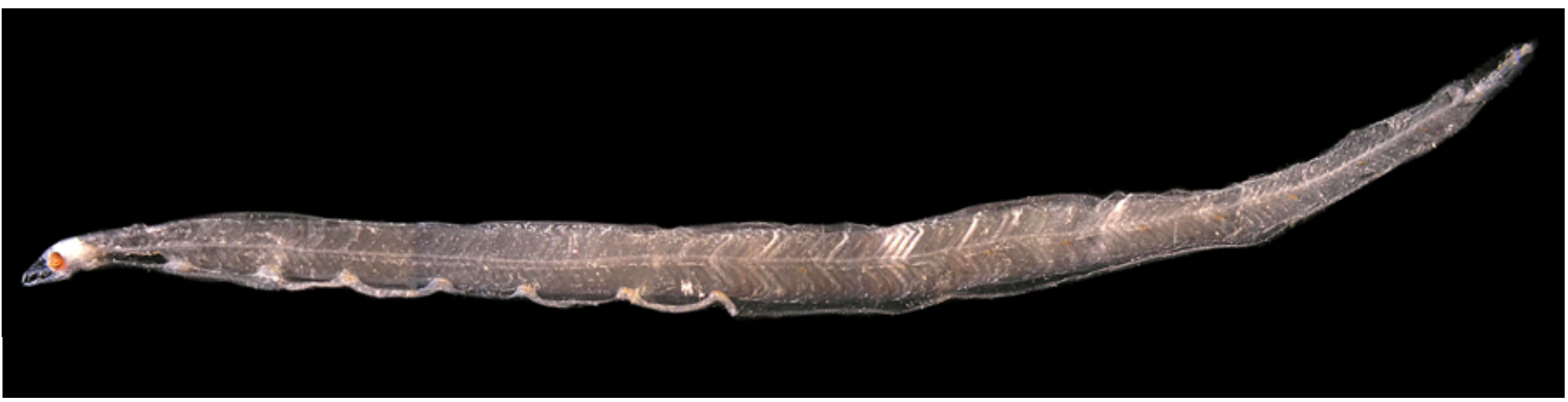

Figura 6: Myrychthys ocellatus DZUFRJ 21616; CP ca 58,0 mm.

\section{Myrychthys ocellatus (Lesueur, 1825)}

Possui sete voltas do intestino bem pronunciadas, com o nefros terminando na última volta. A origem da nadadeira dorsal está situada na altura da primeira volta do intestino em larvas com aproximadamente $80 \mathrm{~mm}$ de comprimento. A pigmentação varia de acordo com o estágio de desenvolvimento da larva. Nos exemplares coletados a pigmentação consiste em linhas oblíquas de pigmentos em alguns miosseptos; 10 a 11 manchas de pigmento na cauda abaixo da notocorda e pequenos melanóforos estrelados em cada volta do intestino. Número total de miômeros: 168; número de miômeros pré-anal: 62-67.

Habitat: espécie marinha, associada a formações coralinas. Vive em águas tropicais.

Nome vulgar: Mututuca.

\section{Georreferenciamento}

\begin{tabular}{|c|c|c|c|c|c|c|c|c|}
\hline DZUFRJ & Latitude (S) & Longitude (W) & Data & $\begin{array}{c}\text { Tipo de } \\
\text { arrasto }\end{array}$ & $\begin{array}{c}\text { Profundidade } \\
\text { de coleta }\end{array}$ & Rede & $\begin{array}{c}\text { Malha } \\
\text { ( } \boldsymbol{\mu m} \text { ) }\end{array}$ & $\begin{array}{c}\mathbf{N} \text {. de } \\
\text { inds. }\end{array}$ \\
\hline 21616 & $22^{\circ} 31^{\prime} 58,9^{\prime \prime}$ & $040^{\circ} 02^{\prime} 53,4^{\prime \prime}$ & $07 / 11 / 2001$ & oblíquo & $1.000 \mathrm{~m}$ & $\begin{array}{c}\text { cilíndrico- } \\
\text { cônica }\end{array}$ & 500 & 1 \\
\hline
\end{tabular}

Referências: Leiby, 1989; Castro \& Bonecker, 2005; Castro \& Bonecker, 2006a. 


\section{Família Congridae}

A família Congridae é marinha e ocorre nas regiões tropicais e temperadas dos oceanos Atlântico, Índico e Pacífico. Compreende 32 gêneros com 160 espécies. As larvas possuem corpo alongado e podem medir entre 90 e $300 \mathrm{~mm}$ de comprimento. As leptocephali dessa família variam muito quanto as principais características de identificação tais como comprimento do intestino e da nadadeira dorsal. A pigmentação ventral está sempre presente, enquanto que a lateral pode ser ausente. Uma característica importante é que o nefros termina a mais de 15 miômeros antes do ânus.

No Brasil já foram identificadas 27 espécies nas fases de larva e adulto. Nesse estudo são contempladas as espécies Ariosoma balearicum, Conger triporiceps e os morfotipos Congridae sp. 1, Congridae sp. 2. 


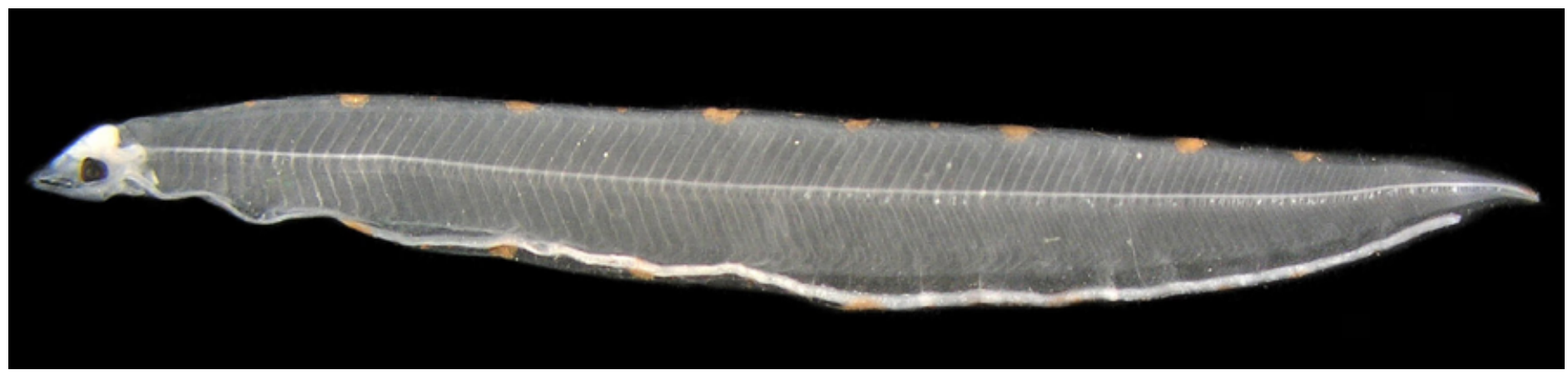

Figura 7 - A: Ariosoma balearicum DZUFRJ 31403; CP 22,7 mm. Vista geral.

\section{Ariosoma balearicum (Delaroche, 1809)}

As larvas com aproximadamente $11 \mathrm{~mm}$ de comprimento possuem sete manchas de pigmentos na margem dorsal do corpo, pigmentos na região ventral do intestino e as linhas oblíquas de pigmentos em cada miossepto já são visíveis. Os exemplares maiores apresentam intestino muito longo, que alcança quase a totalidade do corpo. As nadadeiras dorsal e anal são curtas e estão limitadas à extremidade posterior do corpo. A pigmentação consiste de linhas oblíquas em cada miossepto, desde a cabeça até a cauda; uma série de pequenos melanóforos no esôfago, intestino até o ânus; e uma série de melanóforos pequenos em toda a região dorsal. Número total de miômeros: 126.

Habitat: espécie marinha, associada a formações coralinas. Vive em águas subtropicais e pode ser coletada até $732 \mathrm{~m}$ de profundidade, mas ocorre principalmente até $100 \mathrm{~m}$.

Nome vulgar: Congro das baleares.

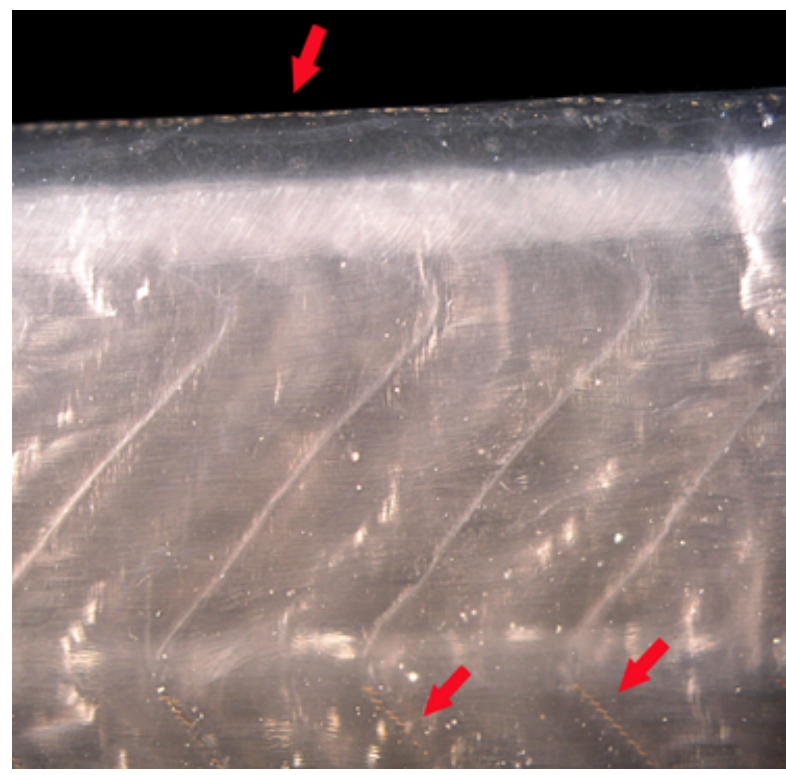

Figura 7 - B: Série de pequenos melanóforos em toda a margem dorsal e nos miosseptos.

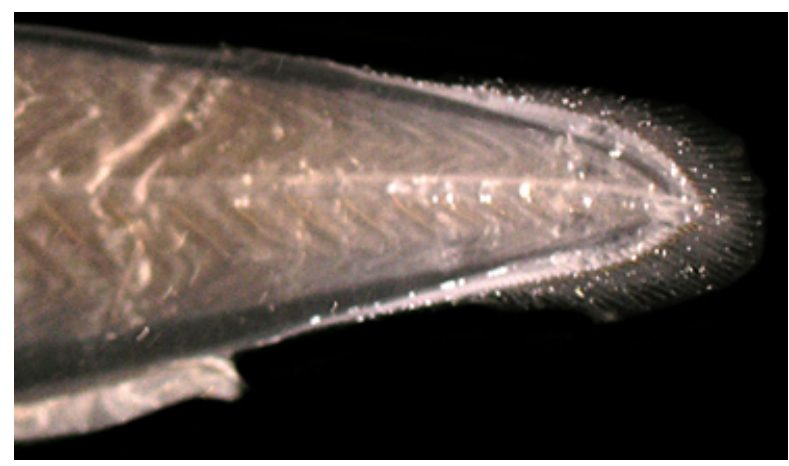

Figura 7 - C: Nadadeiras dorsal e anal.

\section{Georreferenciamento}

\begin{tabular}{|c|c|c|c|c|c|c|c|c|}
\hline DZUFRJ & Latitude (S) & Longitude (W) & Data & $\begin{array}{l}\text { Tipo de } \\
\text { arrasto }\end{array}$ & $\begin{array}{c}\text { Profundidade } \\
\text { de coleta }\end{array}$ & Rede & $\begin{array}{l}\text { Malha } \\
(\mu \mathrm{m})\end{array}$ & $\begin{array}{l}N^{\circ} \text {. de } \\
\text { inds. }\end{array}$ \\
\hline 7517 & $21^{\circ} 57^{\prime} 10,5^{\prime \prime}$ & $039^{\circ} 43^{\prime} 33,3^{\prime \prime}$ & 09/10/2001 & oblíquo & $1.000 \mathrm{~m}$ & cilíndrico-cônica & 500 & 1 \\
\hline 7548 & $21^{\circ} 57^{\prime} 10,5^{\prime \prime}$ & $039^{\circ} 43^{\prime} 33,3^{\prime \prime}$ & 09/10/2001 & oblíquo & $1.000 \mathrm{~m}$ & cilíndrico-cônica & 500 & 1 \\
\hline 7550 & $21^{\circ} 58^{\prime} 31,0^{\prime \prime}$ & $039^{\circ} 50^{\prime} 29,7^{\prime \prime}$ & $11 / 10 / 2001$ & oblíquo & $1.000 \mathrm{~m}$ & cilíndrico-cônica & 500 & 1 \\
\hline
\end{tabular}

Referências: Smith, 1989c; Castro \& Bonecker, 2005; Castro \& Bonecker, 2006a. 


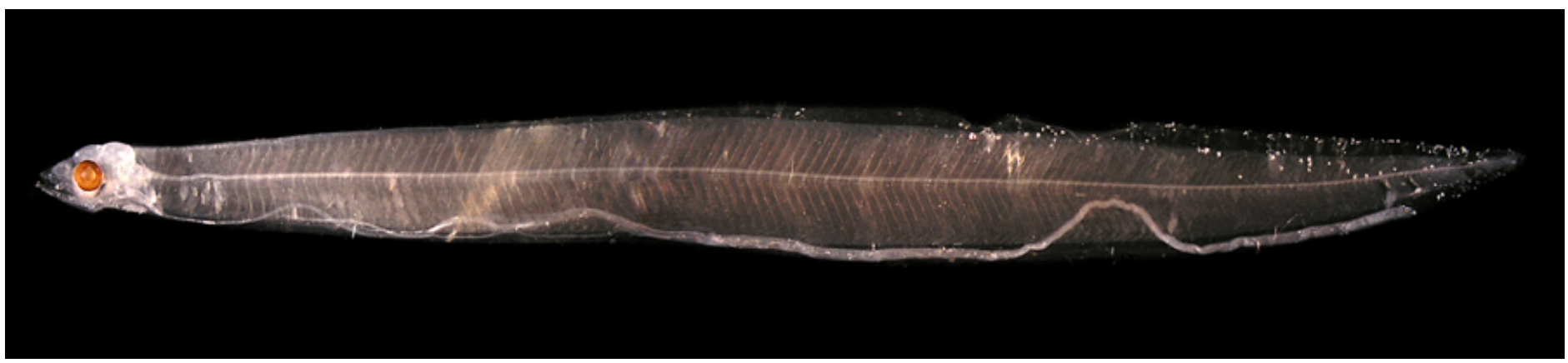

Figura 8: Conger triporiceps DZUFRJ 21611; CP 36,3 mm.

\section{Conger triporiceps Kanazawa, 1958}

Essa espécie não apresenta pigmentos na lateral do corpo e possui uma mancha de pigmentos abaixo do olho. Apresenta pequenos melanóforos ao longo do intestino. Número total de miômeros: 153-156.

Habitat: espécie marinha, associada a formações coralinas. Vive em águas tropicais até a profundidade de $55 \mathrm{~m}$.

Nome vulgar: Congro dentão.

\section{Georreferenciamento}

\begin{tabular}{|c|c|c|c|c|c|c|c|c|}
\hline DZUFRJ & Latitude (S) & Longitude (W) & Data & $\begin{array}{c}\text { Tipo de } \\
\text { arrasto }\end{array}$ & $\begin{array}{c}\text { Profundidade } \\
\text { de coleta }\end{array}$ & Rede & $\begin{array}{c}\text { Malha } \\
\text { ( } \boldsymbol{\mu m} \text { ) }\end{array}$ & $\begin{array}{c}\mathbf{N}^{\circ} \text {. de } \\
\text { inds. }\end{array}$ \\
\hline 21611 & $22^{\circ} 32^{\prime} 49,0^{\prime \prime}$ & $040^{\circ} 04^{\prime} 20,9^{\prime \prime}$ & $07 / 11 / 2001$ & oblíquo & $1.000 \mathrm{~m}$ & $\begin{array}{c}\text { cilíndrico- } \\
\text { cônica }\end{array}$ & 500 & 1 \\
\hline
\end{tabular}

Referências: Smith, 1989c; Castro \& Bonecker, 2005; Castro \& Bonecker, 2006a. 


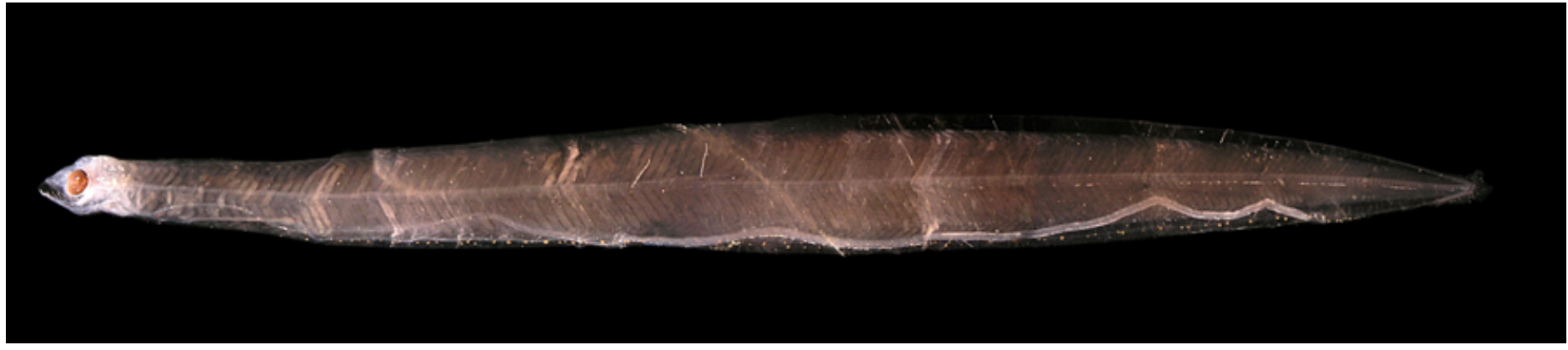

Figura 9 - A: Congridae sp. 1 DZUFRJ 7546; CP 58,5 mm. Vista geral.

\section{Congridae sp. 1}

Apresenta uma mancha de pigmentos abaixo do olho e pigmentos nos raios da nadadeira caudal. Possui pigmentos pequenos abaixo da linha lateral a cada 5-8 miômeros e pigmentos maiores na margem ventral do intestino. Número de miômeros pré-anais: 124. Número total de miômeros: 155-157.

Habitat: todas as espécies da família Congridae são marinhas.

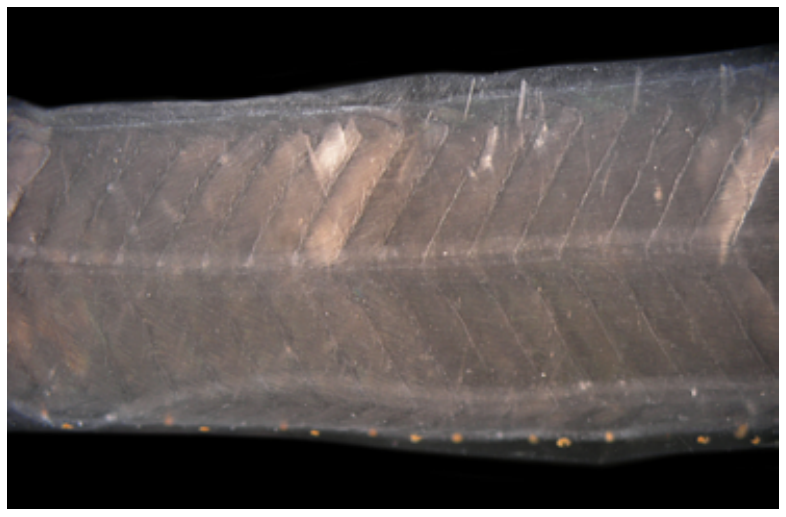

Figura 9 - C: Pigmentos maiores na margem ventral do intestino.

\section{Georreferenciamento}

\begin{tabular}{|c|c|c|c|c|c|c|c|c|}
\hline DZUFR & Latitude (S) & Longitude (W) & Data & $\begin{array}{c}\text { Tipo de } \\
\text { arrasto }\end{array}$ & $\begin{array}{c}\text { Profundidade } \\
\text { de coleta }\end{array}$ & Rede & $\begin{array}{c}\text { Malha } \\
(\boldsymbol{\mu m})\end{array}$ & $\begin{array}{c}\mathbf{N}^{\circ} \text {. de } \\
\text { inds. }\end{array}$ \\
\hline 5431 & $22^{\circ} 31^{\prime} 40,9^{\prime \prime}$ & $040^{\circ} 02^{\prime} 39,6^{\prime \prime}$ & $07 / 11 / 2001$ & oblíquo & $1.000 \mathrm{~m}$ & cilíndrico-cônica & 500 & 1 \\
\hline 7519 & $21^{\circ} 58^{\prime} 31,0^{\prime \prime}$ & $039^{\circ} 50^{\prime} 29,7^{\prime \prime}$ & $10 / 10 / 2001$ & oblíquo & $1.000 \mathrm{~m}$ & cilíndrico-cônica & 500 & 13 \\
\hline 7520 & $21^{\circ} 58^{\prime} 31,0^{\prime \prime}$ & $039^{\circ} 50^{\prime} 29,7^{\prime \prime}$ & $11 / 10 / 2001$ & oblíquo & $1.000 \mathrm{~m}$ & cilíndrico-cônica & 500 & 8 \\
\hline 7546 & $21^{\circ} 54^{\prime} 36,5^{\prime \prime}$ & $039^{\circ} 45^{\prime} 20,0^{\prime \prime}$ & $10 / 10 / 2001$ & oblíquo & $1.000 \mathrm{~m}$ & cilíndrico-cônica & 500 & 1 \\
\hline 21539 & $22^{\circ} 32^{\prime} 490^{\prime \prime}$ & $040^{\circ} 04^{\prime} 2 \mathbf{1}^{\prime \prime}$ & $07 / 11 / 2001$ & oblíquo & $1.000 \mathrm{~m}$ & cilíndrico-cônica & 500 & 3 \\
\hline
\end{tabular}

Referências: Smith, 1989c.

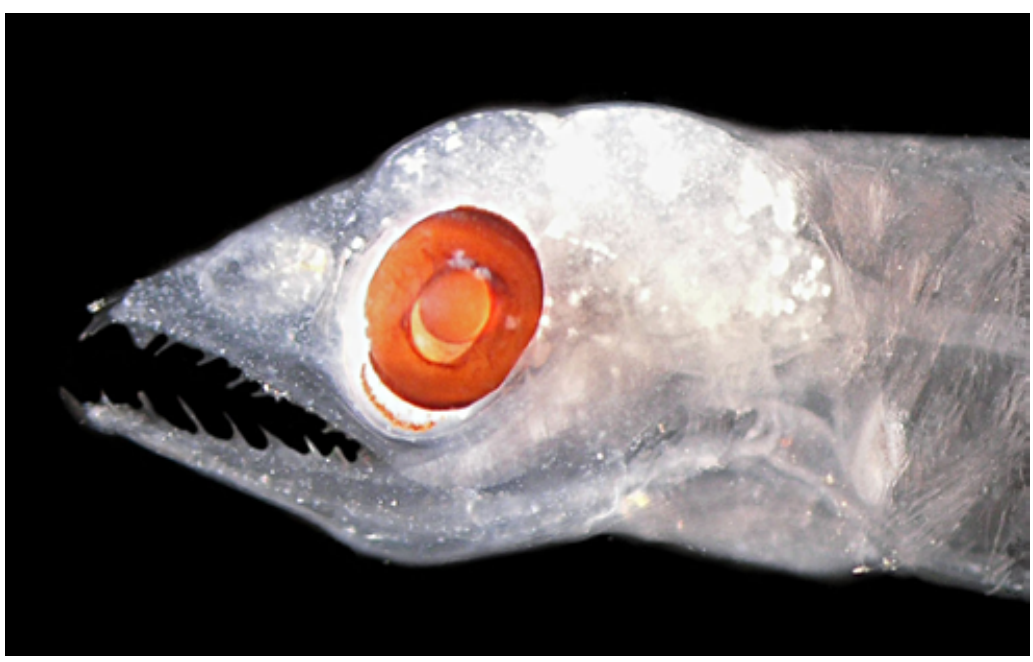

Figura 9 - B: Presença de uma mancha de pigmentos abaixo do olho.

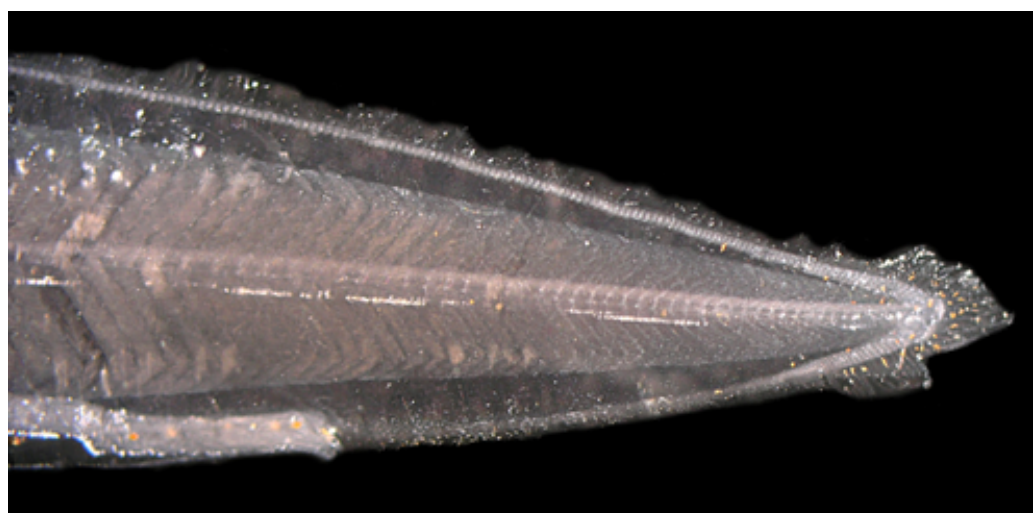

Figura 9 - D: Nadadeira caudal pigmentada. 


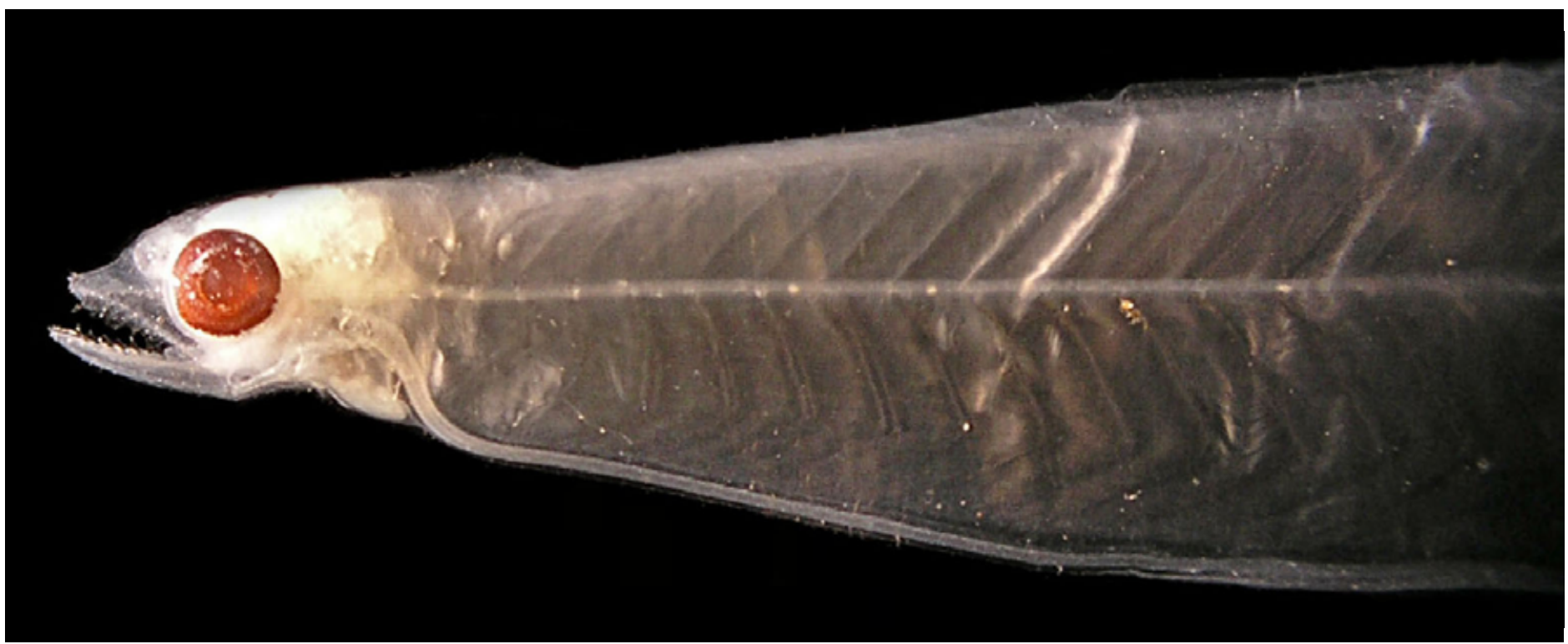

Figura 10 - A: Congridae sp. 2 DZUFRJ 21540; CP 105,0 mm. Vista geral.

\section{Congridae sp. 2}

Possui linhas diagonais de pigmentos em cada miômero logo abaixo da linha lateral. O intestino termina junto com a cauda que é muito arredondada. Número de miômeros anais: 88 . Número total de miômeros: 88.

Habitat: todas as espécies da família Congridae são marinhas.

\section{Georreferenciamento}

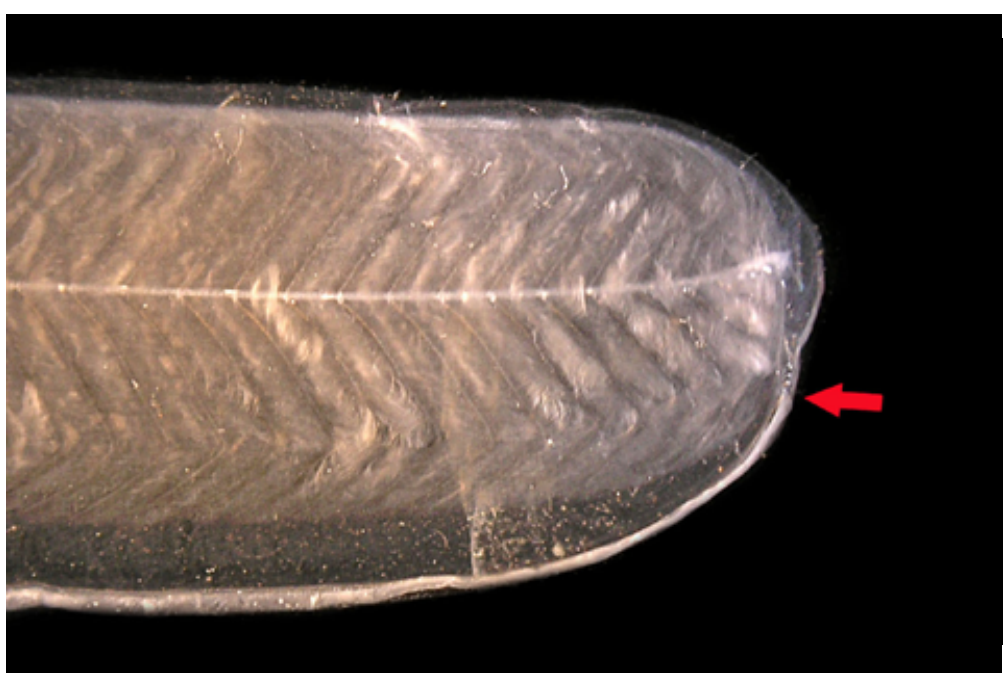

Figura 10 - B: Ânus localizado próximo a nadadeira caudal.

\begin{tabular}{|c|c|c|c|c|c|c|c|c|}
\hline DZUFRJ & Latitude (S) & Longitude (W) & Data & $\begin{array}{c}\text { Tipo de } \\
\text { arrasto }\end{array}$ & $\begin{array}{c}\text { Profundidade } \\
\text { de coleta }\end{array}$ & Rede & $\begin{array}{c}\text { Malha } \\
\text { ( } \boldsymbol{\mu m})\end{array}$ & $\begin{array}{c}\mathbf{N}^{\circ} \text {. de } \\
\text { inds. }\end{array}$ \\
\hline 21540 & $22^{\circ} 31^{\prime} 40,9^{\prime \prime}$ & $040^{\circ} 02^{\prime} 39,6^{\prime \prime}$ & $07 / 11 / 2001$ & oblíquo & $1.000 \mathrm{~m}$ & cilíndrico-cônica & 500 & 1 \\
\hline
\end{tabular}

Referências: Smith, 1989c. 


\section{Família Nemichthyidae}

A família Nemichthyidae é marinha e as espécies possuem hábitos meso e batipelágicos. Ocorre nos oceanos Atlântico, Índico e Pacífico. Compreende três gêneros com nove espécies. As larvas são grandes e finas atingindo 300-400 mm de comprimento. O intestino é longo e reto; o ânus está situado próximo ao final da cauda que é afilada. O padrão de pigmentação é variável e importante para a identificação das espécies.

No Brasil já foram identificadas cinco espécies nas fases de larva e adulto: Avocettina acuticeps (Regan, 1916); Avocettina infans (Günther, 1878); Labichthys carinatus Gill \& Ryder, 1883; Nemichthys curvirostris (Strömman, 1896) e Nemichthys scolopaceus Richardson, 1848. Nesse estudo é contemplada a espécie Nemichthys sp. 


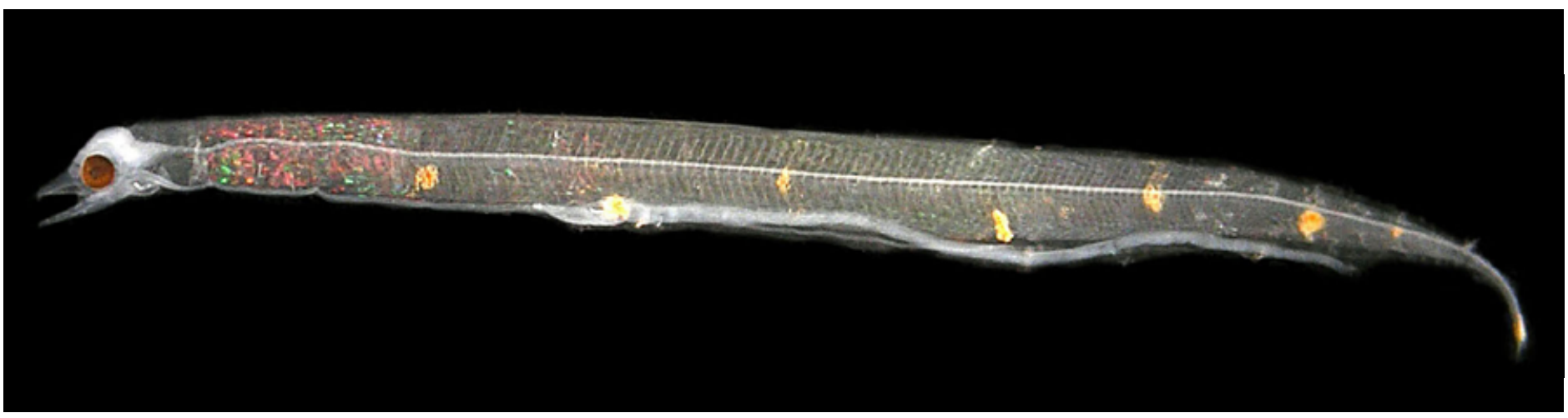

Figura 11: Nemichthys sp. DZUFRJ 7549; CP 8,5 mm.

\section{Nemichthys sp.}

Nos exemplares pequenos existem duas manchas grandes de pigmento na região ventral do corpo que são perdidas quando a larva atinge aproximadamente $60 \mathrm{~mm}$ de comprimento. As larvas de Nemichthys são muito longas e apresentam cauda filiforme. Têm mais miômeros que as demais larvas dessa família, variando entre 300 e 400 ou mais. No Brasil já foram registradas as espécies Nemichthys scolopaceus Richardson, 1848 e Nemichthys curvirostris Strömman, 1896.

Habitat: as três espécies descritas na literatura são marinhas, têm hábitos mesopelágicos e habitam grandes profundidades, até $2.000 \mathrm{~m}$.

\section{Georreferenciamento}

\begin{tabular}{|c|c|c|c|c|c|c|c|c|}
\hline DZUFR & Latitude (S) & Longitude (W) & Data & $\begin{array}{c}\text { Tipo de } \\
\text { arrasto }\end{array}$ & $\begin{array}{c}\text { Profundidade } \\
\text { de coleta }\end{array}$ & Rede & $\begin{array}{c}\text { Malha } \\
\text { ( } \boldsymbol{\mu m} \text { ) }\end{array}$ & $\begin{array}{c}\mathbf{N}^{\circ} \text {. de } \\
\text { inds. }\end{array}$ \\
\hline 7549 & $21^{\circ} 54^{\prime} 36,5^{\prime \prime}$ & $039^{\circ} 45^{\prime} 20,0^{\prime \prime}$ & $10 / 10 / 2001$ & oblíquo & $1.000 \mathrm{~m}$ & $\begin{array}{c}\text { cilíndrico- } \\
\text { cônica }\end{array}$ & 500 & 1 \\
\hline
\end{tabular}

Referências: Smith, 1989d; Castro \& Bonecker, 2005; Castro \& Bonecker, 2006a. 


\section{Família Nettastomatidae}

A família Nettastomatidae é marinha e ocorre nos oceanos Atlântico, Índico e Pacífico. Compreende seis gêneros com aproximadamente 38 espécies. As larvas podem alcançar até $200 \mathrm{~mm}$ de comprimento, possuem corpo alto ou comprido e cauda afilada. O intestino é curto com ondulações ou duas voltas distintas, alcançando menos da metade do comprimento total. A nadadeira dorsal é longa se originando logo após a cabeça.

No Brasil já foram identificadas nove espécies nas fases de larva e adulto. Nesse estudo são contempladas as espécies Facciolella sp. e Saurenchelys sp. 


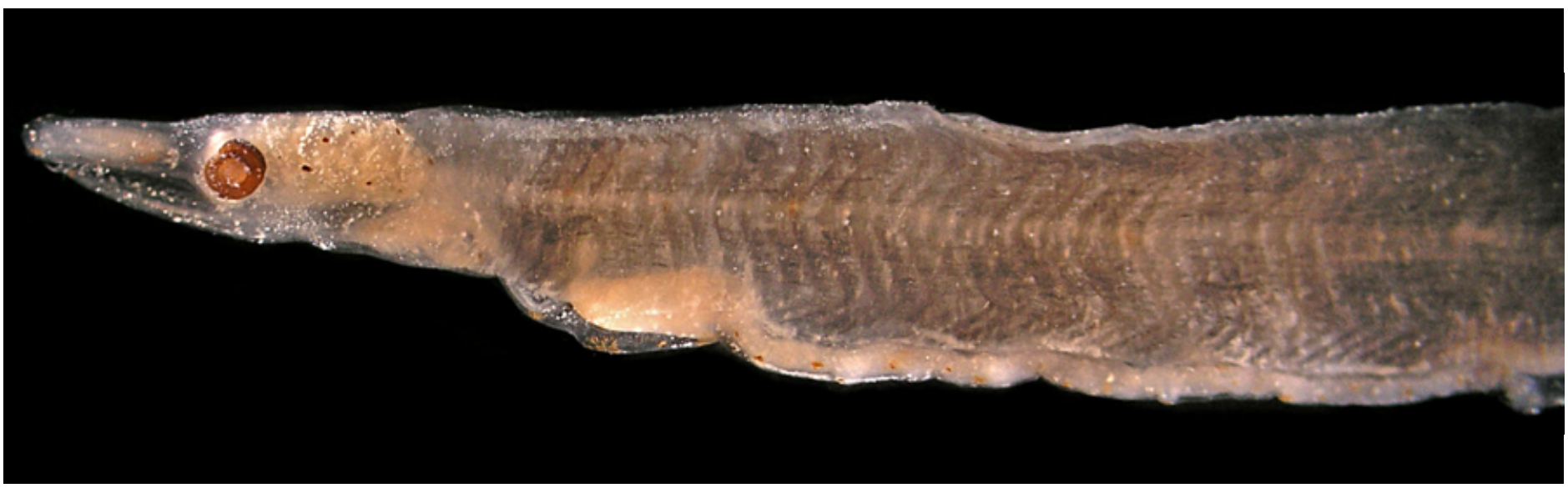

Figura 12: Facciolella sp. DZUFRJ 7518; CP 99,0 mm.

\section{Facciolella sp.}

As larvas de Facciolella possuem corpo longo e estreito, com cauda afilada. O intestino é curto, tem ondulações irregulares e uma série de melanóforos grandes. A nadadeira dorsal é longa e começa pouco depois da nadadeira peitoral. A cabeça é longa e o focinho é afilado. A pigmentação da região lateral do corpo varia entre as espécies, mas de maneira geral elas possuem pigmentos no intestino e no cérebro. O número de miômeros varia entre 240 e 264.

Habitat: as espécies de Facciolella são marinhas, algumas são demersais, batipelágicas, batidemersais ou bentopelágicas. Vivem em águas profundas e já foram registradas em 3.109 m de profundidade. Normalmente, ocorrem entre 329 e $732 \mathrm{~m}$. De acordo com a literatura, as espécies denominadas Facciolella sp. B e Facciolella sp. C já foram coletadas na região oceânica do Brasil.

\section{Georreferenciamento}

\begin{tabular}{|c|c|c|c|c|c|c|c|c|}
\hline DZUFRJ & Latitude (S) & Longitude (W) & Data & $\begin{array}{c}\text { Tipo de } \\
\text { arrasto }\end{array}$ & $\begin{array}{c}\text { Profundidade } \\
\text { de coleta }\end{array}$ & Rede & $\begin{array}{c}\text { Malha } \\
\text { ( } \boldsymbol{\mu m} \text { ) }\end{array}$ & $\begin{array}{c}\mathbf{N}^{\circ} \text {. de } \\
\text { inds. }\end{array}$ \\
\hline 7518 & $21^{\circ} 58^{\prime} 31,0^{\prime \prime}$ & $039^{\circ} 50^{\prime} 29,7^{\prime \prime}$ & $11 / 10 / 2001$ & oblíquo & $1.000 \mathrm{~m}$ & $\begin{array}{c}\text { cilíndrico- } \\
\text { cônica }\end{array}$ & 500 & 1 \\
\hline
\end{tabular}

Referências: Smith, 1989e; Castro \& Bonecker, 2005; Castro \& Bonecker, 2006a; Fahay, 2007. 


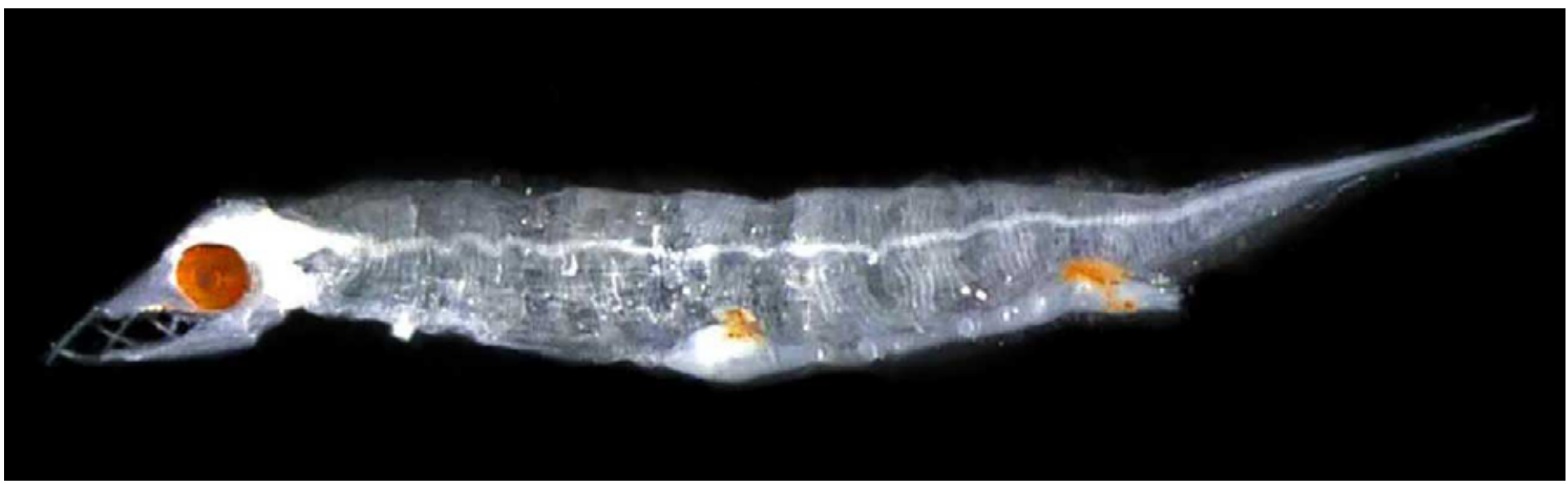

Figura 13: Saurenchelys sp. DZUFRJ 22076; CP 5,3 mm.

\section{Saurenchelys sp.}

Os exemplares pequenos possuem duas manchas grandes de pigmentos sobre as duas voltas do intestino, que continuam nos exemplares maiores, um pouco mais dispersas. As larvas de Saurenchelys são caracterizadas por apresentarem corpo longo e estreito, com cauda afilada. O intestino é relativamente curto, com duas voltas pequenas distintas. A nadadeira dorsal é longa e começa na altura da primeira volta do intestino. A pigmentação da região lateral do corpo varia entre as espécies, mas de maneira geral há uma série de melanóforos internos próximo à notocorda, na região da cauda. Possuem pigmentos sobre as voltas do intestino e no palato. O número de miômeros varia entre 192 e 276. No Brasil há registros das espécies Saurenchelys cancrivora Peters, 1864 e Saurenchelys stylura (Lea, 1913).

Habitat: todas as espécies de Saurenchelys registradas na literatura são marinhas. A maioria é demersal, ocorrendo até $700 \mathrm{~m}$ de profundidade.

\section{Georreferenciamento}

\begin{tabular}{|c|c|c|c|c|c|c|c|c|}
\hline DZUFRJ & Latitude (S) & Longitude (W) & Data & $\begin{array}{c}\text { Tipo de } \\
\text { arrasto }\end{array}$ & $\begin{array}{c}\text { Profundidade } \\
\text { de coleta }\end{array}$ & Rede & $\begin{array}{c}\text { Malha } \\
\text { ( } \boldsymbol{\mu m} \text { ) }\end{array}$ & $\begin{array}{c}\mathbf{N}^{\circ} \text {. de } \\
\text { inds. }\end{array}$ \\
\hline 21612 & $22^{\circ} 34^{\prime} 05,0^{\prime \prime}$ & $040^{\circ} 19^{\prime} 40,0^{\prime \prime}$ & $17 / 05 / 2002$ & oblíquo & $600 \mathrm{~m}$ & $\begin{array}{c}\text { cilíndrico- } \\
\text { cônica }\end{array}$ & 500 & 2 \\
\hline 22076 & $22^{\circ} 38^{\prime} 25,0^{\prime \prime}$ & $040^{\circ} 17^{\prime} 41,0^{\prime \prime}$ & $19 / 05 / 2002$ & oblíquo & $40 \mathrm{~m}$ & bongô & 500 & 1 \\
\hline
\end{tabular}

Referências: Smith \& Castle, 1982; Smith, 1989e; Castro \& Bonecker, 2005; Castro \& Bonecker, 2006a. 